\title{
PENGARUH PENDEKATAN TAKTIS TERADAP KEMAMPUAN BERMAIN HOKI DAN PEMBENTUKAN KERJASAMA
}

\author{
Novi Nurlathifah, Helmy Firmansyah \\ Universitas Pendidikan Indonesia \\ email : novi.nurlathifah@yahoo.com
}

\begin{abstract}
Abstrak
Penelitian ini bertujuan untuk mengetahui bagaimana pengaruh model pembelajaran pendekatan taktis terhadap kemampuan bermain hoki dan pembentukan kerjasama siswa di SMA Negeri 26 Bandung. Metode penelitian yang digunakan adalah metode eksperimen. Dasar penggunaan metode ini yaitu untuk melakukan percobaan untuk sesuatu hal yang akan diketahui pengaruh dan akibat dari perlakuan atau treatment yang dilakukan. Perlakuan yang diberikan yaitu sebanyak 16 kali pertemuan. Populasi dan sampel yaitu siswa yang mengikuti kegiatan ekstrakurikuler hoki di SMA Negeri 26 Bandung. Teknik pengambilan sampel yaitu sampling jenuh sebanyak 30 orang. Instrumen penelitian yang digunakan yaitu berupa lembar observasi kemampuan bermain hoki dan lembar observasi kerjasama. Dari hasil pengolahan dan analisis data yang dilakukan, diperoleh thitung (2.4728) $>t_{\text {tabel }}(1,6723)$ dengan demikian hipotesis nol $\left(\mathrm{H}_{0}\right)$ ditolak. Maka, dapat disimpulkan bahwa pendekatan taktis memberikan pengaruh yang signifikan terhadap kemampuan bermain hoki dan pembentukan kerjasama siswa di SMA Negeri 26 Bandung.
\end{abstract}

Kata kunci: Pendekatan Taktis, Kemampuan Bermain Hoki, Pembentukan Kerjasama.

\section{A. PENDAHULUAN}

Pendidikan jasmani sudah tidak dapat dipisahkan dari sistem pendidikan nasional. Hal ini dapat diamati dari wajibnya pendidikan jasmani diselenggarakan di setiap jenjang dan tingkat pendidikan. Pendidikan jasmani dilaksanakan dalam kegiatan intrakurikuler dan ekstrakurikuler. Pendidikan jasmani yang dilaksanakan dalam kegiatan intrakurikuler merupakan kegiatan aktivitas jasmani yang terdapat dalam mata pelajaran pendidikan jasmani di jam pelajaran sekolah, sedangkan kegiatan ekstrakurikuler merupakan kegiatan aktivitas jasmani yang dilaksanakan di luar jam pelajaran sekolah. Seperti yang dipaparkan oleh Departemen Pendidikan dan Kebudayaan (Rahmawati, 2013, hlm. 2-3) menjelaskan bahwa:

Ekstrakurikuler adalah kegiatan jam pelajaran sekolah yang biasa dilakukan di luar sekolah dengan tujuan untuk memperluas pengetahuan siswa mengenai hubungan antara berbagai mata pelajaran, menyalurkan bakat dan minat serta melengkapi pembinaan seutuhnya. Kegiatan ini dilakukan berkaitan atau hanya dalam waktu-waktu tertentu dan ikut dinilai. Kegiatan ekstrakurikuler yang diikuti oleh siswa bertujuan agar siswa dapat mengembangkan bakat, minat, serta kemampuannya, untuk meraih prestasi yang maksimal baik di lingkungan sekolah 
maupun di luar sekolah. Kegiatan ekstrakurikuler yang ada di sekolah tentu berbedabeda jenisnya. Kegiatan dari ekstrakurikuler ini sendiri dapat berbentuk kegiatan pada seni, olahraga, pengembangan kepribadian, dan kegiatan lain yang bertujuan positif untuk kemajuan dari siswa-siswi itu sendiri. Dengan beberapa kegiatan ekstrakurikuler yang ada, siswa dapat memilih kegiatan yang sesuai dengan kemampuan dan minat masing-masing. Olahraga merupakan salah satu kegiatan ekstrakurikuler pada pembelajaran pendidikan jasmani, contohnya seperti silat, karate, bolavoli, bolabasket, futsal, sepakbola, dan termasuk ekstrakurikuler hoki.

Hoki merupakan salah satu olahraga permainan yang dapat dilakukan oleh pria dan wanita dan dimainkan oleh dua regu yang setiap pemainnya menggunakan suatu tongkat yang ujungnya melengkung (stick) dan bola. Tujuan dari permainan hoki adalah memasukan bola sebanyak-banyaknya ke gawang lawan untuk memperoleh kemenangan, dimana untuk memperoleh kemenangan itu perlu upaya mempertahankan gawang sendiri dari serangan lawan dan kemampuan mengolah bola ketika penyerangan. Hal tersebut hanya dapat dilakukan dengan cara kerjasama dari tiap pemainnya melalui penggunaan teknik dan strategi bermain.

Untuk dapat memasukan bola ke gawang lawan dibutuhkan keterampilan teknik dasar yang baik, kemampuan dalam bermain, serta kerjasama antar anggota tim. Tetapi, dalam melakukan permainan hoki kemampuan dan keterampilan siswa yang berbeda-beda membuat siswa sulit untuk bekerjasama, sehingga nilai kerjasama terasa sangat kurang ketika permainan berlangsung. Untuk itu perlu adanya model pembelajaran yang tepat digunakan dalam permainan hoki tentunya yang dapat meningkatkan kemampuan dalam bermain hoki dan membentuk kerjasama siswa.

Dalam permainan hoki terdapat beberapa keterampilan teknik dasar yang harus dikuasai. Menurut Hermanu (dalam Rahmawati, 2013, hlm. 3-4) keterampilan teknik dasar yang harus dikuasai di antaranya keterampilan "Push (mendorong), hit (memukul), stop (menahan), dribble (menggiring), flick (mencungkil bola), jab (menjangkau bola), tackle (merampas bola), dan scoop (mengangkat bola)". Permainan hoki mengenal akan konsep penyerangan dan pertahanan, mengenal juga posisi pemain seperti pemain depan (penyerang), pemain tengah (gelandang), dan pemain belakang (bek). Konsep penyerangan dan bertahan harus diketahui oleh siswa sehingga siswa mampu mengetahui bagaimana melakukan pola pertahanan dan bagaimana pola penyerangan, agar tujuan dari permainan hoki yaitu memasukan bola ke gawang lawan sebanyak-banyaknya dapat tercapai.

Dalam cabang olahraga permainan, keseimbangan keterampilan teknik dan penampilan bermain sangat dibutuhkan. Untuk menguasai kemampuan bermain dalam olahraga permainan contohnya seperti hoki, tidak hanya cukup dengan menguasai keterampilan teknik memainkan bola, namun keterampilan-keterampilan gerak lain untuk mendukung pemain yang membawa bola. Sebagaimana dijelaskan oleh Subroto (2010, hlm. 11) bahwa:

Penampilan bermain adalah tidak hanya terbatas pada pelaksanaan keterampilan gerak dan teknik, namun juga komponen-komponen lain seperti membuat keputusan, mendukung pemain lain atau supporting, membatasi 
ruang gerak lawan, menutup kawan seregu, mengatur posisi untuk mengembangkan permainan, memastikan lapangan yang memadai, atau menutup lapangan dengan posisi dasar.

Hoki merupakan permainan beregu yang dimainkan oleh beberapa orang dalam satu tim. Dalam permainan beregu dibutuhkan kerjasama yang baik di antara para pemainnya untuk mencapai kemenangan. Menurut Polak M. (dalam Sumardiyanto dkk., 2010, hlm. 123) menyatakan bahwa "Kerjasama atau kooperasi (cooperation) adalah gejala saling mendekati untuk mengurus kepentingan bersama dan tujuan bersama". Dalam permainan beregu dibutuhkan kerjasama yang baik dan kompak agar terjalin komunikasi yang baik sesama anggota tim untuk kepentingan bersama dan tujuan bersama yang diharapkan oleh semua anggota tim.

Dalam perkembangannya, ternyata dalam pembelajaran pendidikan jasmani banyak sekali berkembang model-model pembelajaran. Dengan menerapkan banyak model pembelajaran maka akan sangat mendukung terhadap terbentuknya pembelajaran yang dapat membuat siswa aktif, inovatif, kreatif, efektif, juga menyenangkan, sehingga tujuan pembelajaran pun akan tercapai. Dalam meningkatkan kemampuan bermain hoki dan pembentukan kerjasama siswa, penulis mencoba menerapkan pendekatan taktis dalam permainan hoki. Melalui pendekatan taktis siswa didorong untuk memecahkan masalah taktik dalam permainan. Dengan menggunakan pendekatan taktis, siswa semakin memahami kaitan antara teknik dan taktik dalam suatu permainan. Sebagaimana Subroto (2010, hlm. 6) menyebutkan bahwa:

Tujuan pendekatan taktis dalam pembelajaran cabang olahraga permainan adalah untuk meningkatkan kesadaran siswa tentang konsep bermain melalui penerapan teknik yang tepat sesuai dengan masalah atau situasi dalam permainan.

Pendekatan taktis mengembangkan strategi pengajarannya yaitu game-drillgame, yang lebih menekankan pada situasi bermain. Dengan menggunakan pendekatan taktis siswa menjadi lebih tertarik dan mendukung minat siswa dalam mengikuti pembelajaran, karena siswa merasa berada dalam situasi bermain yang sebenarnya. Namun, di dalamnya siswa tetap diberikan pembelajaran teknik-teknik dalam permainan hoki tersebut. Dengan diterapkannya model pendekatan taktis diharapkan dapat meningkatkan kemampuan siswa dalam bermain hoki dan dapat membentuk kerjasama siswa.

\section{METODE}

Metode yang digunakan penulis dalam penelitian ini adalah metode eksperimen. Sugiyono (2013, hlm. 107) menjelaskan bahwa "Metode penelitian eksperimen dapat diartikan sebagai metode penelitian yang digunakan untuk mencari pengaruh perlakuan tertentu terhadap yang lain dalam kondisi yang terkendalikan." Metode eksperimen dilakukan untuk melihat ada tidaknya sebab akibat dari suatu perlakuan tertentu terhadap kelompok uji coba. Dapat dikatakan 
penelitian eksperimen ini dilakukan untuk melihat terdapat atau tidaknya hubungan sebab akibat dari variabel-variabel yang akan diteliti. Dalam penelitian ini, peneliti mencobakan model pembelajaran pendekatan taktis untuk diketahui pengaruhnya terhadap kemampuan bermain hoki dan pembentukan kerjasama siswa.

Populasi dan sampel dalam penelitian ini adalah siswa dan siswi SMA Negeri 26 Bandung yang mengikuti kegiatan ekstrakurikuler hoki. Teknik pengambilan sampel yaitu sampling jenuh sebanyak 30 orang.

Instrumen yang digunakan dalam penelitian ini adalah lembar observasi kemampuan bermain hoki dan lembar observasi kerjasama. Dalam melakukan observasi, peneliti hanya berperan sebagai guru atau pemberi treatment. Sedangkan yang menjadi pengobservasi (observer) yaitu guru pendidikan jasmani yang menjadi pembina dalam ekstrakurikuler hoki di sekolah tersebut atau pelatih hoki di sekolah tersebut, karena telah mengetahui, memahami, dan mengenal masing- masing siswa yang mengikuti kegiatan ekstrakurikuler hoki. Observer hanya berperan sebagai seseorang yang mengamati kemampuan bermain dari setiap siswa ketika permainan berlangsung dan tidak terlibat dalam kegiatan pembelajaran di lapangan. Dengan menggunakan lembar observasi ini, hasil yang ingin diperoleh dengan menggunakan beberapa indikator yang telah dijabarkan lebih dapat dipercaya dan sistematis. Kategori penilaian yang digunakan adalah skala likert.

\section{Tabel 1}

Kategori Penilaian dengan Menggunakan Skala Likert

\begin{tabular}{lr} 
Sangat Baik & 4 \\
Baik & 3 \\
Tidak Baik & 2 \\
Sangat Tidak Baik & $: 1$ \\
\hline
\end{tabular}

Tabel 2

Indikator Kemampuan Bermain Hoki

\begin{tabular}{|c|c|}
\hline $\begin{array}{c}\text { Sub } \\
\text { Komponen }\end{array}$ & Indikator \\
\hline \multirow[t]{4}{*}{$\begin{array}{l}\text { Kemampuan } \\
\text { Bermain Hoki }\end{array}$} & $\begin{array}{l}\text { Mengolah bola menurut Clarke (dalam Indriansah, 2013, } \\
\text { hlm. 15) }\end{array}$ \\
\hline & $\begin{array}{l}\text { Pergerakan tanpa bola menurut Anders (dalam Anugrah, } \\
\text { 2013, hlm. 12) }\end{array}$ \\
\hline & $\begin{array}{l}\text { Mempertahankan gawang menurut Hermanu (dalam } \\
\text { Rahmawati, 2013, hlm. 10) }\end{array}$ \\
\hline & $\begin{array}{lccc}\text { Menyerang gawang menurut } & \text { Hermanu } & \text { (dalam } \\
\text { Rahmawati, 2013, hlm. 10) } & & \\
\end{array}$ \\
\hline
\end{tabular}


Tabel 3

Indikator Kerjasama

\begin{tabular}{|c|c|}
\hline Sub Komponen & Indikator \\
\hline \multirow{2}{*}{$\begin{array}{l}\text { Kerjasama } \\
\text { menurut }\end{array}$} & 1. Mengikuti aturan \\
\hline & 2. Membantu teman yang belum bisa \\
\hline Suherman (2001, & 3. Ingin semua teman bermain dan berhasil \\
\hline \multirow{8}{*}{ hlm. 86) } & 4. Memotivasi orang lain \\
\hline & 5. Bekerja keras menerapkan skill \\
\hline & 6. Hormat terhadap orang lain \\
\hline & 7. Mengendalikan tempramen \\
\hline & 8. Memperhatikan perasaan orang lain \\
\hline & 9. Kerjasama meraih tujuan \\
\hline & 10. Menerima pendapat orang lain \\
\hline & 11. Bermain secara terkendali \\
\hline
\end{tabular}

\section{HASIL PENELITIAN}

a. Uji Normalitas

Tabel 4

Hasil Pengujian Normalitas Liliefors

Dari Data Pre-test dan Post-test Kemampuan Bermain Hoki

\begin{tabular}{ccccc}
\hline Jenis Tes & Jumlah Sampel & $\mathbf{L}_{\text {hitung }}$ & $\mathbf{L}_{\text {tabel }}$ & Kesimpulan \\
\hline Pre-test & 30 & 0,157 & 0,161 & NORMAL \\
\hline Post-test & 30 & 0,150 & 0,161 & NORMAL
\end{tabular}

Berdasarkan Tabel 4 di atas dengan taraf nyata $\alpha=0,05$ dan jumlah sampelnya adalah 30 orang dapat diketahui bahwa hasil pre-test dan post-test kemampuan bermain hoki masing-masing mempunyai nilai $\mathrm{L}_{\text {hitumg }}\left(\mathrm{L}_{0}\right)$ sebesar 0,157 dan 0,150 dengan nilai $\mathrm{L}_{\text {tabel }}$ sebesar 0,161 . Kriteria pengujian hipotesisnya adalah: Tolak hipotesis nol $\left(\mathrm{H}_{0}\right)$ jika $\mathrm{L}_{\text {hitung }}\left(\mathrm{L}_{0}\right)$ lebih besar daripada $\mathrm{L}_{\text {tabel, }}$ dalam hal lainnya hipotesis nol $\left(\mathrm{H}_{0}\right)$ diterima. Maka untuk data pre-test nilai $\mathrm{L}_{\text {hitung }}(0,157)<\mathrm{L}_{\text {tabel }}$ $(0,161)$ dan untuk data post-test nilai $\mathrm{L}_{\text {hitung }}(0,150)<\mathrm{L}_{\text {tabel }}(0,161)$ sehingga hipotesis diterima yang artinya data pre-test dan post-test tersebut berdistribusi normal.

Tabel 5

Hasil Pengujian Normalitas Liliefors

Dari Data Pre-test dan Post-test Pengukuran Kerjasama

\begin{tabular}{ccccc}
\hline Jenis Tes & Jumlah Sampel & $\mathbf{L}_{\text {hitung }}$ & $\mathbf{L}_{\text {tabel }}$ & Kesimpulan \\
\hline Pre-test & 30 & 0,131 & 0,161 & NORMAL \\
\hline Post-test & 30 & 0,120 & 0,161 & NORMAL
\end{tabular}


Berdasarkan Tabel 5 di atas dengan taraf nyata $\alpha=0,05$ dan jumlah sampelnya adalah 30 orang dapat diketahui bahwa hasil pre-test dan post-test pengukuran kerjasama siswa masing-masing mempunyai nilai $\mathrm{L}_{\text {hitumg }}\left(\mathrm{L}_{0}\right)$ sebesar 0,131 dan 0,120 dengan nilai $\mathrm{L}_{\text {tabel }}$ sebesar 0,161 . Kriteria pengujian hipotesisnya adalah: Tolak hipotesis nol $\left(\mathrm{H}_{0}\right)$ jika $\mathrm{L}_{\text {hitung }}\left(\mathrm{L}_{0}\right)$ lebih besar daripada $\mathrm{L}_{\text {tabel }}$, dalam hal lainnya hipotesis nol $\left(\mathrm{H}_{0}\right)$ diterima. Maka untuk data pre-test nilai $\mathrm{L}_{\text {hitung }}(0,131)$

$<\mathrm{L}_{\text {tabel }}(0,161)$ dan untuk data post-test nilai $\mathrm{L}_{\text {hitung }}(0,120)<\mathrm{L}_{\text {tabel }}(0,161)$ sehingga hipotesis diterima yang artinya data pre-test dan post-test tersebut berdistribusi normal.

Tabel 6

Hasil Pengujian Normalitas Liliefors

Dari Data Pre-test dan Post-test Gabungan Antara Kemampuan Bermain Hoki dan Kerjasama

\begin{tabular}{ccccc}
\hline Jenis Tes & Jumlah Sampel & $\mathbf{L}_{\text {hitung }}$ & $\mathbf{L}_{\text {tabel }}$ & Kesimpulan \\
\hline Pre-test & 30 & 0,152 & 0,161 & NORMAL \\
\hline Post-test & 30 & 0,134 & 0,161 & NORMAL \\
\hline
\end{tabular}

Berdasarkan Tabel 6 di atas dengan taraf nyata $\alpha=0,05$ dan jumlah sampelnya adalah 30 orang dapat diketahui bahwa hasil pre-test dan post-test gabungan antara kemampuan bermain hoki dan kerjasama siswa masing-masing mempunyai nilai Lhitumg $\left(\mathrm{L}_{0}\right)$ sebesar 0,152 dan 0,134 dengan nilai $\mathrm{L}_{\text {tabel }}$ sebesar 0,161. Kriteria pengujian hipotesisnya adalah: Tolak hipotesis nol $\left(\mathrm{H}_{0}\right)$ jika $\mathrm{L}_{\text {hitung }}\left(\mathrm{L}_{0}\right)$ lebih besar daripada $\mathrm{L}_{\text {tabel}}$, dalam hal lainnya hipotesis nol $\left(\mathrm{H}_{0}\right)$ diterima. Maka untuk data pretest nilai $\mathrm{L}_{\text {hitung }}(0,152)<\mathrm{L}_{\text {tabel }}(0,161)$ dan untuk data post-test nilai $\mathrm{L}_{\text {hitung }}(0,134)$ $<\mathrm{L}_{\text {tabel }}(0,161)$ sehingga hipotesis diterima yang artinya data pre-test dan post-test tersebut berdistribusi normal.

a. Uji Homogenitas

Tabel 7

Hasil Perhitungan Uji Homogenitas Kemampuan Bermain Hoki

\begin{tabular}{ccccc}
\hline Jenis Tes & Jumlah Sampel & $\mathbf{F}_{\text {hitung }}$ & $\mathbf{F}_{\text {tabel }}$ & Kesimpulan \\
\hline $\begin{array}{c}\text { Pre-test dan } \\
\text { Post-test }\end{array}$ & 30 & 1,6521 & 1,85 & HOMOGEN \\
& & & & \\
\hline
\end{tabular}

Kriteria pengujian homogenitas tersebut adalah: Tolak hipotesis nol $\left(\mathrm{H}_{0}\right)$ jika $\mathrm{F}_{\text {hitung }}$ lebih besar daripada $\mathrm{F}_{\text {tabel }}$, dalam hal lainnya hipotesis nol $\left(\mathrm{H}_{0}\right)$ diterima. Dari tabel 7 di atas taraf nyata $\alpha=0,05$ dan $\mathrm{dk}\left(\mathrm{n}_{1}-1 ; \mathrm{n}_{2}-1\right)$ dapat diketahui bahwa data hasil pre-test dan post-test kemampuan bermain hoki mempunyai $\mathrm{F}_{\text {hitung }}=1,6521$ dan $F_{\text {tabel }}=1,85$. Oleh karena $F_{\text {hitung }}(1,6521)<F_{\text {tabel }}(1,85)$ maka 
hipotesisnya diterima bahwa tidak terdapat variansi yang signifikan atau data tersebut dinyatakan homogen.

\section{Tabel 8}

Hasil Perhitungan Uji Homogenitas Kerjasama

\begin{tabular}{ccccc}
\hline Jenis Tes & Jumlah Sampel & $\mathbf{F}_{\text {hitung }}$ & $\mathbf{F}_{\text {tabel }}$ & Kesimpulan \\
\hline $\begin{array}{c}\text { Pre-test dan } \\
\text { Post-test }\end{array}$ & 30 & 1,1669 & 1,85 & HOMOGEN \\
\hline
\end{tabular}

Dari tabel 8 di atas taraf nyata $\alpha=0,05$ dan $\mathrm{dk}\left(\mathrm{n}_{1}-1 ; \mathrm{n}_{2}-1\right)$ dapat diketahui bahwa data hasil pre-test dan post-test pengukuran kerjasama siswa mempunyai $F_{\text {hitung }}=1,1669$ dan $F_{\text {tabel }}=1,85$. Oleh karena $F_{\text {hitung }}(1,1669)<F_{\text {tabel }}(1,85)$ maka hipotesisnya diterima bahwa tidak terdapat variansi yang signifikan atau data tersebut dinyatakan homogen.

Tabel 9

Hasil Perhitungan Uji Homogenitas Gabungan Antara Kemampuan Bermain Hoki dan Kerjasama

\begin{tabular}{ccccc}
\hline Jenis Tes & Jumlah Sampel & $\mathbf{F}_{\text {hitung }}$ & $\mathbf{F}_{\text {tabel }}$ & Kesimpulan \\
\hline $\begin{array}{c}\text { Pre-test } \text { dan } \\
\text { Post-test }\end{array}$ & 30 & 1,5431 & 1,85 & HOMOGEN \\
\hline
\end{tabular}

Dari tabel 9 di atas taraf nyata $\alpha=0,05$ dan $\mathrm{dk}\left(\mathrm{n}_{1}-1 ; \mathrm{n}_{2}-1\right)$ dapat diketahui bahwa data hasil pre-test dan post-test gabungan antara kemampuan bermain hoki dan kerjasama siswa mempunyai $F_{\text {hitung }}=1,5431$ dan $F_{\text {tabel }}=1,85$. Oleh karena $F_{\text {hitung }}$ $(1,5431)<\mathrm{F}_{\text {tabel }}(1,85)$ maka hipotesisnya diterima bahwa tidak terdapat variansi yang signifikan atau data tersebut dinyatakan homogen.

b. Uji Hipotesis

Tabel 10

Hasil Uji Hipotesis Kesamaan Dua Rata-rata $(\mu)$ : Uji Satu Pihak Kemampuan Bermain Hoki

\begin{tabular}{cccc}
\hline Jenis Tes & $\mathbf{t}_{\text {hitung }}$ & $\mathbf{t}_{\text {tabel }}$ & Keterangan \\
\hline Pre-test dan Post-test & 2,3300 & 1,6723 & SIGNIFIKAN
\end{tabular}


Dari Tabel 10 di atas diketahui thitung kemampuan bermain hoki didapat 2,3300 $>$ dari tabel 1,6723 maka $\mathrm{H}_{0}$ ditolak dan $\mathrm{H}_{1}$ diterima. Maka dengan demikian pengaruh pendekatan taktis terhadap kemampuan bermain hoki berbeda signifikan pada saat post-test.

\section{Tabel 11}

Hasil Uji Hipotesis Kesamaan Dua Rata-rata $(\mu)$ : Uji Satu Pihak Kerjasama

\begin{tabular}{cccc}
\hline Jenis Tes & $\mathbf{t}_{\text {hitung }}$ & $\mathbf{t}_{\text {tabel }}$ & Keterangan \\
\hline Pre-test dan Post-test & 2,1825 & 1,6723 & SIGNIFIKAN \\
\hline
\end{tabular}

Dari Tabel 11 di atas diketahui thitung kerjasama didapat 2,1825 > dari $t_{\text {tabel }}$ 1,6723 maka $\mathrm{H}_{0}$ ditolak dan $\mathrm{H}_{1}$ diterima. Maka dengan demikian pengaruh pendekatan taktis terhadap pembentukan kerjasama berbeda signifikan pada saat post-test.

\section{Tabel 12}

Hasil Uji Hipotesis Kesamaan Dua Rata-rata $(\mu)$ : Uji Satu Pihak Gabungan Antara Kemampuan Bermain Hoki dan Kerjasama

\begin{tabular}{cccc}
\hline Jenis Tes & $\mathbf{t}_{\text {hitung }}$ & $\mathbf{t}_{\text {tabel }}$ & Keterangan \\
\hline Pre-test dan Post-test & 2,4728 & 1,6723 & SIGNIFIKAN \\
\hline
\end{tabular}

Dari Tabel 12 di atas diketahui thitung gabungan antara kemampuan bermain hoki dan kerjasama didapat 2,4728 > dari $\mathrm{t}_{\text {tabel }}$ 1,6723 maka $\mathrm{H}_{0}$ ditolak dan $\mathrm{H}_{1}$ diterima. Maka dengan demikian pengaruh pendekatan taktis terhadap kemampuan bermain hoki dan pembentukan kerjasama berbeda signifikan pada saat post-test.

\section{DISKUSI PENEMUAN}

Berdasarkan hasil perhitungan atau analisis data, penulis menemukan hasil yang menunjukan bahwa model pembelajaran pendekatan taktis memberikan pengaruh yang signifikan terhadap kemampuan bermain hoki dan pembentukan kerjasama siswa. Hal ini sesuai yang disampaikan oleh Subroto (2010, hlm. 5) bahwa tujuan mengajar dengan pendekatan taktis bagi siswa adalah:

1. Meningkatkan kemampuan bermain melalui pemahaman terhadap keterkaitan antara taktik permainan dan perkembangan keterampilan.

2. Memberikan kesenangan dalam proses pembelajaran.

3. Belajar memecahkan masalah-masalah dan membuat keputusan selama bermain.

Hal ini dikarenakan dalam kegiatan pembelajaran model pendekatan taktis, aktivitas yang diberikan berupa aktivitas bermain, sehingga pembelajaran lebih 
menarik yang memberikan pengalaman-pengalaman yang nyata dimana siswa terlihat lebih merasa senang dan aktif serta tidak merasa jenuh dan bosan dalam mengikuti kegiatan permainan, dan masalah-masalah taktik yang ditemukan oleh siswa dipecahkan dengan mengambil keputusan-keputusan yang benar ketika kegiatan pembelajaran hoki, yang tentunya berpengaruh terhadap penampilan bermain siswa sehingga kemampuan bermain hoki siswa akan meningkat.

Penggunaan model pendekatan taktis tersebut memberikan pengaruh terhadap potensi lain yang ada dalam diri siswa itu sendiri, seperti interaksi sosial, pengalaman berpartisipasi dan pemecahan masalah, serta belajar kerjasama, karena ketika siswa melakukan bentuk-bentuk kegiatan permainan yang diberikan, menuntut siswa untuk berkomunikasi dan saling bekerjasama dengan siswa yang lainnya agar mencapai tujuan dari tugas gerak atau permainan yang diberikan. Kerjasama ini tidak hanya terlihat ketika dalam permainan saja, di luar permainan pun ketika proses pembelajaran siswa menunjukan sikap-sikap yang menunjukan kerjasama. Hal ini sesuai dengan pendapat Hoerunisa (2013, hlm. 69) bahwa:

Pembentukan nilai kerjasama dalam kegiatan pendekatan taktis yaitu karena pendekatan ini lebih identik dalam kegiatan bermain, dimana siswa menjadi lebih terangsang untuk lebih saling menjaga kekompakan satu sama lainnya. Siswa lebih semakin memahami arti kerjasama antar anggotanya atau kelompok karena pengulangan kegiatan bermain yang sering dilakukan pada setiap pembelajaran pendekatan taktis tersebut.

Terciptanya kerjasama siswa dalam proses pembelajaran mengakibatkan adanya interaksi yang baik sesama siswa hal ini mendukung pula terhadap kemampuan bermain siswa itu sendiri. Dengan demikian pendekatan taktis dapat memberikan hasil yang signifikan terhadap kemampuan bermain hoki dan pembentukan kerjasama siswa.

\section{KESIMPULAN}

Kesimpulan dari penelitian ini adalah terdapat pengaruh yang signifikan dari model pendekatan taktis terhadap kemampuan bermain hoki dan pembentukan kerjasama siswa di SMA Negeri 26 Bandung. 


\section{REFERENSI}

Abduljabar, B. (2009) Manajemen Pendidikan Jasmani dan Olahraga. Bandung: FPOK UPI Anugrah, S.M. (2013) Perbandingan Pembelajaran Taktis dan Teknis Terhadap Motivasi Siswa Dalam Pembelajaran Hoki di SMA Negeri 26 Bandung. Skipsi pada FPOK UPI Bandung: Tidak diterbitkan

Hoerunisa, N. (2013) Pengaruh Pendekatan Taktis Terhadap Hasil Belajar Permainan Bola Tangan dan implikasinya Terhadap Nilai-nilai Kerjasama. Skipsi pada FPOK UPI Bandung: Tidak diterbitkan

Indriansah, D. (2013) Hubungan Antara Tingkat Kecemasan dan kepercayaan Diri Siswa SMAN 26 Bandung Dalam Permainan Hoki. Skripsi pada FPOK UPI Bandung: Tidak diterbitkan

Rahmawati, P. (2013) Pengaruh Senam Otak (Brain Gym) Terhadap Pemahaman Bermain Hoki. Skripsi pada FPOK UPI Bandung: Tidak diterbitkan

Subroto, T. (2010) Didaktik Metodik Pembelajaran Olahraga Permainan. Bandung: FPOK UPI

Sugiyono. (2013) Metode Penelitian Pendidikan. Bandung: Alfabeta

Suherman. (2001) Evaluasi Pendidikan Jasmani. Jakarta

Sumardiyanto, dkk. (2010) Sejarah dan Filsafat Olahraga. Bandung: FPOK UPI

Undang-undang Republik Indonesia No 20 Tahun 2003 [Online]. Tersedia di: http://www.kemenag.go.id/file/dokumen/UU2003.pdf [Diakses 7 Oktober 2014) 